\title{
THE ROLE OF SHORT ANSWER QUESTIONS IN DEVELOPING HIGHER ORDER THINKING
}

Cheryl Chamberlain*, Alison Button, Laura Dison, Stella Granville, Elizabeth Delmont University of the Witwatersrand

The Humanities Faculty at the University of the Witwatersrand has introduced a number of one-year foundation courses to provide support to students and to enable those from a disadvantaged educational system to enter the academic environment. The focus in this paper is on the role of short answer questions in the assessment of higher order thinking. Short answer questions have traditionally been thought to assess factual recall and lower levels of response. We argue that short answer questions have the potential to assess a range of competencies including higher order thinking. We argue that short answer questions help to support student learning of disciplinary concepts and skills by breaking down and sequencing final summative assessment tasks into smaller manageable tasks. We examine the relationship between higher order thinking and modes of assessment, and develop a taxonomy to show the relationship between task words and levels of intellectual performance. This may be used to align course assessment with learning outcomes and teaching practices.

\section{INTRODUCTION}

This paper results from collaborative research at the University of the Witwatersrand, (Wits) Johannesburg, involving the Humanities Faculty teaching and learning advisors and teachers in a number of different disciplines (Applied English Language Studies (AELS), Geography, and History of Art) all of whom are involved directly or indirectly in foundation course teaching, assessment practices and curriculum design.

\section{AIMS AND FOCUS OF THE PAPER}

Our focus in this paper is on the role of short answer questions in the assessment of higher order thinking. Short answer questions have traditionally been thought to assess factual recall. Initially when our disparate group of researchers began to investigate the extent to which higher order thinking was incorporated into our exam questions, we found that students experienced unexpected difficulties with short answer questions. On reflection, and after analysis of our questions, it became apparent that multiple levels of difficulty and demand were embedded in our questions. In fact, higher levels of thinking were required by our short answer questions.

We see short answer questions as having the following characteristics: they are less than a paragraph in length and have a point-to-mark relationship. These characteristics require 
students to respond to the task in a concise and very specific way. The questions do not give students the leeway to include any irrelevant or superfluous information. Students therefore have the added pressure of having to be highly selective in addressing the question. Short answer questions are linguistically and cognitively demanding in a way we had not anticipated. Although all three sets of tasks demonstrated in this paper appear to be disparate, our argument is that they share the characteristics mentioned earlier. In this paper we demonstrate how short answer questions have the potential to assess a range of competencies including higher order thinking. In addition, we argue that short answer questions help to support student learning of disciplinary concepts and skills by breaking down and sequencing final summative assessment tasks into smaller and manageable tasks.

We examine, therefore, the relationship between higher order thinking and modes of assessment and develop a taxonomy to show the relationship between task words and levels of intellectual performance. This taxonomy (Figure 1) may be used to align course assessment with learning outcomes and teaching practices and this is demonstrated in detailed case studies. These case studies from different disciplines: Visual Literacy, Environmental Issues and Applied English Language Studies, had different intentions. Visual Literacy used the short answer questions in order to scaffold an essay prompt, Environmental Issues examined the extent to which students had mastered conceptual issues of varying difficulty and in Applied English Language Studies, students were expected to demonstrate application of particular academic skills

\section{CONTEXT: FOUNDATION COURSES AT THE UNIVERSITY OF THE WITWATERSRAND}

From 1992, as part of the transformation process, the Humanities Faculty at Wits introduced a number of one-year foundation courses. These were intended to provide academic support to students and to enable those from a disadvantaged educational system to enter the academic environment at the tertiary level. By 1996, students in the Humanities Faculty had a choice of five foundation courses: Applied English Language Studies (AELS), English Literature (which by 1998 was also geared towards students entering the discipline of African literature), Geography, Sociology and Visual Literacy. A sixth foundation course, from the Department of International Relations, was added in 1999. All of these courses, except for Geography, have been modularized into two discrete semester-long components

\section{Background to the Applied English Language Studies (AELS) foundation course}

The first AELS module is an introduction to 'Academic Literacy' and is mainly designed to support students working in the social sciences. 'Academic Literacy' introduces students to the language and learning of university level work. This involves developing the language proficiency of the students by providing practice in oral and written work relevant to university studies. A second module, entitled 'Language and Research Practices' introduces foundation students to the processes that lie behind the academic texts that they are required to read at a university. The course requires students to conduct and write up a small-scale research project. Students formulate questions, design the research process, collect and analyze data, draw conclusions and present their findings both orally and in writing. Students are provided with constant support and mediation throughout the project. 
Both of these modules work to develop higher order thinking by providing learning tasks which are carefully scaffolded throughout. During each module a number of short writing tasks build the skills necessary for the main essay assessment of the semester. Tutors work formatively with essay drafts and the end of the term culminates in a final examination - a summative assessment in which competencies are tested.

\section{Background to the Geography foundation course}

The Foundation in Environmental Issues was the first foundation course to be set up in 1992 'The Foundation in Environmental Issues is a foundation course which specifically attempts to redress the effects of apartheid education and aims to give students an understanding of how knowledge and learning are organized in Geography. There is a focus on academic reading and writing skills, graphicacy and numeracy; with an emphasis on interactive teaching and learning' (Foundation in Environmental Issues flier, 2005). In addition to the generic skills developed, there is a strong spatial component to the Environmental Issues Foundation course which encourages students to gain an understanding of the relationships and processes within and between physical, imagined and socially-constructed spaces.

Assessment in this course takes a number of forms: there is an emphasis on writing as a powerful means of formative and summative assessment. The writing focus has led to a writing-rich programme which scaffolds and sequences student learning. During the course of the year dependency on staff assessment gives way to peer assessment and finally to selfreflection.

\section{Background to the Visual Literacy foundation course}

Visual Literacy is an interdisciplinary foundation course piloted by three departments: Fine Arts, History of Art and Dramatic Art.

Andrew (1998:2) identifies five theoretical principles which underpin the course:

- 'the primacy of student 'voice', personal history and the personal archive

- the focus on production, as opposed to consumption of meaning and knowledge

- the process of making and reading as something that is inherently self-reflective

- the ability to transfer that which is experienced in the course into the real world and viceversa

- the realization that one's position is an ongoing negotiation of meaning. This applies to the interaction between staff and students and between staff themselves'.

Assessment practices, pedagogy and course content are multi-modal and multi-faceted. Assessment is both formative and summative. Formative assessment includes: short pieces of written work, longer assignments, presentations, a journal, practical work (like making a video), a performance which ties together the many aspects of the course, a critical review of this performance, and examinations. While the year end examination is truly summative, the mid-year exam is both formative and summative as it provides the locus for extensive discussion at the beginning of the second module. Lecturers note any conceptual gaps evident in students' thinking and writing and use this information to frame the curriculum and pedagogy in the second module. 


\section{THE ROLE OF ASSESSMENT IN STUDENT LEARNING}

\section{The relationship between higher order thinking and modes of assessment}

We start this paper from the premise that one of the central aims of foundation courses is to develop higher order thinking as it relates to specific disciplinary contexts. Intellectual complexity is fundamental to the academic endeavour. 'The internal structure of academic ideas, arguments and conceptions tends to be complex, and is usually more complex than the everyday conception of the same phenomenon' (Laurillard, 1993:53). It is essential therefore to promote higher order learning in foundation courses so that students move beyond surface rote learning of a received body of knowledge to a higher level of conceptual and critical analysis. Without a higher order perspective of a discipline, students will merely engage at the 'content' level in terms of Perkins' (1992) levels of understanding. Meta-cognition is highly valued as a higher order self-reflective ability. It requires 'thinking about thinking' and being aware of one's own processes of learning and understanding. In order to impact on student approaches to learning, the existing departmentally-based foundation courses were developed to

... provide the learning contexts for students to develop and utilize strategies that yield deeper understandings of the complex disciplinary understandings rather than relying on surface learning strategies like memorization (Alfred et al, 1998:2).

\section{The levels of performance in higher order thinking}

We have developed a taxonomy of learning derived from Bloom (1956) and Perkins (1992) incorporating a range of approaches and explanations for classifying intellectual performance (using Biggs's terminology to classify the various levels at which assessment tasks are directed). Bloom's 1956 taxonomy, a model which is widely accessible and used in teacher development, consists of six classes: knowledge, comprehension, application, analysis, synthesis and evaluation. Bloom suggests that learners acquire understanding and competence in stages beginning with 'lower order' tasks (knowledge and comprehension) which are cognitively simple or easy to understand. These knowledges may be explicitly presented, concrete and accessible and require low level inferencing skills. Middle and higher order skills require application, analysis, synthesis and evaluation. Some of the implications underpinning this model are that higher order learning involves being able, for example:

- to apply a theory or concept to a range of different examples/situations

- to make connections between ideas which involves analysis and synthesis

- to understand what a concept is as well as understanding the concept of a theory, both of which imply a higher level of abstraction rather than concrete descriptive literalness

- to understand the notion of a position

- to generate questions

- to internalize new bodies of knowledge and make them meaningful and relevant

- to generate new bodies of knowledge

- to be self-reflective about the learning process

Rowntree (1987) raises a number of problems regarding Bloom's taxonomy. The hierarchical development of skills may imply that 'later' classes in the taxonomy build on and 
incorporate 'earlier ones' in a neat and orderly fashion, which is not always the case. For example: 'Some types of comprehension might incorporate elements of application or analysis; some kinds are only possible through synthesis' (Rowntree, 1987:104). Similarly Resnick (1987) warns of the dangers of separating out the different levels of the taxonomy at different levels of education. This is because higher order thinking needs to be cultivated at all stages of intellectual development. 'The idea that knowledge must be acquired first and that its application to reasoning and problem-solving can be delayed is a persistent one in educational thinking. Hierarchies of educational objectives, although intended to promote attention to higher order skills, paradoxically feed this belief by suggesting that knowledge acquisition is a first stage in the sequence of educational goals' (Resnick,1987:8). Despite these criticisms, Bloom still provides one useful perspective on higher order thinking.

Therefore all levels of Bloom's taxonomy, not only the most advanced class (evaluation), need to be integrated into a teaching programme at increasing levels of conceptual complexity. Perkins (1992) provides a useful alternative to Bloom's categories of how students acquire understanding within a discipline. 'Students should be given opportunities to display the following four levels of understanding :

- content knowledge -the student has acquired facts, concepts and routine procedures of the discipline

- problem-solving knowledge -the student can solve typical formulaic problems in the discipline

- epistemic knowledge - the student has an awareness of what learning and understanding in the discipline demands, has some idea of the historical and philosophical development of the discipline and thus has sufficient meta-knowledge to undertake justificatory and explanatory tasks within the discourse and conventions of the discipline

- inquiry knowledge - the student knows how to challenge assumptions, results, etc. within the discipline and knows how to construct new knowledge within the discipline' (Perkins, 1992 in Luckett, 1996:47).

The central framework for assessment developed in this paper is a modified version of Biggs's SOLO taxonomy. Biggs developed the SOLO taxonomy, which he refers to as the 'framework for understanding understanding' (1999:37). SOLO stands for the Structure of Observed Learning Outcomes and describes how a student's performance grows in complexity when mastering academic tasks. The taxonomy can be used both for defining curriculum objectives, which outline where students should be functioning hierarchically, and for 'evaluating learning outcomes so that we know at what level individual students actually are operating' (ibid). The SOLO taxonomy provides an opportunity for scaffolding formative and summative tasks by using a 'staircase of verbs' which relate to each level of understanding.

Our assessment framework shows the different levels at which students address assessment tasks. The purpose of our synthesis (Figure 1) is two-fold: firstly it enables us to identify the levels of student competency, and secondly it enables teachers to construct assessment questions at each level in order to elicit higher level answers. For a scheme like this to be adopted as a guiding principle throughout a course, there needs to be a 'commitment to devising the kinds of assessment tasks which allow students to perform at the highest levels' (Toohey, 1999:172). 
1. PRESTRUCTURAL LEVEL:

- Student misses the point and/or connections between ideas (Biggs)

- Student has not brought any structure to the learning

\section{MULTISTRUCTURAL LEVEL:}

- Student's response focuses on several relevant features but they are not co-ordinated together or integrated (Biggs)

- Student has ability to rephrase knowledge (some evidence of understanding, coverage and effort) (Bloom)

- Student can perform simple applications of content, e.g. provide illustrations (Bloom) but is unable to think through the implications of specific applications

- Student can solve typical formulaic problems in the discipline (Perkins)

\section{Task words:}

describe, list, explain, combine

\section{UNISTRUCTURAL LEVEL:}

- Student's response focuses on ONE relevant aspect only

- Student cannot see more than one dimension in the structure of the material being considered (Biggs)

- Student has knowledge of terminology and facts (Bloom)

- Student does basic information processing-perceiving, reading, computing and memorising

Task words: identify, outline

\section{RELATIONAL LEVEL:}

- Student can integrate several parts into a coherent whole and details are linked to conclusions (Biggs)

- Student shows clear understanding of major concepts and can understand the question, put up a good argument and show judgement about what is important and what is less important

- Student has ability to break problem into its constituent parts and establish the relationships between each one (Bloom)

- Student has ability to combine separate elements into a whole (Bloom)

Task words:

apply, analyse, relate, compare/contrast

\section{METACOGNITIVE LEVEL/HIGHER ORDER THINKING}

- Student gains an awareness of what learning and understanding in the discipline demands and can conduct justificatory and explanatory "understanding performances": (Perkins)

[Refer to Perry's scheme of cognitive development where students move from basic dualism (authorities know the right answers), multiplicity (everyone has a right to their own opinions) relativism (everything is relative but not equally valid) to evolving commitments (standing up for one's own values and positions).]

- Student has the ability to make judgements about the value of something with reference to appropriate criteria (Bloom)

- Student has metacognitive thinking processes-can self monitor performance at each level and has the ability to self-reflexively evaluate and correct how information is processed (Kitchener)

- The response generalises the structure beyond the information that is given and higher order thinking is used to extrapolate to other situations. It is characterised by a high level of abstract thinking which enables the student to generalise to new contexts, make applications or draw conclusions that are apparently original (Biggs)

- Student has the capacity to think epistemologically, to recognise and evaluate assumptions and limits of theories of knowledge and is able to suggest alternatives

Task words: critically assess, evaluate, theorise, generalise, hypothesise, reflect

Figure 1: The relationship between task words and levels of intellectual performance. (Adapted from Bloom, 1956; Perkins, 1992; Biggs, 1999) 


\section{Higher order thinking: the role of the language}

Our thinking around the pivotal role of prior knowledge and experience in student learning is theorized by Cummins (1996) who suggests that 'context-embedded' material is more accessible to learners, especially those who are operating in an additional language. This is because such material is more closely related to the world of the learner and to familiar experiences and concepts. Unfamiliar material is 'context-reduced' and requires from the learner a far wider frame of reference. Such unfamiliar material, according to Cummins, may however be either cognitively demanding or cognitively undemanding.

Context-embedded material provides the learner with support for expressing or receiving ideas. The language of such materials is supported by cultural relevance, prior experience and a range of 'interpersonal and situational cues' (Cummins, 1996:58). These factors are of particular significance for first year students at the University of the Witwatersrand, some of whom come from rural areas of the country and disadvantaged educational backgrounds. In addition to the cognitive and linguistic demands of the University, students are faced with an unfamiliar or alienating institutional environment.

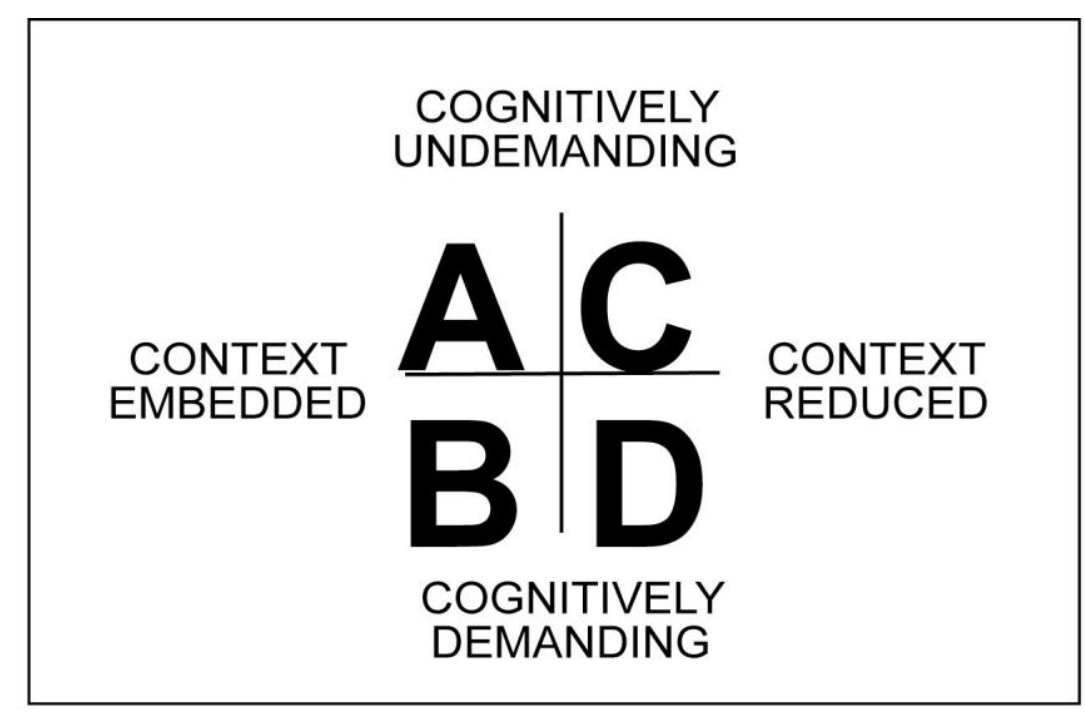

Figure 2: Cummins' model: Range of contextual support and degree of cognitive involvement in communicative activities. (Cummins, 1996)

In dealing with cognitively demanding and context-reduced materials, students are only 'minimally supported by contextual or interpersonal cues' and are required to make complex meanings 'by means of language itself' (Cummins, 1996:58) without the assistance of a conversational partner or familiar subject matter. Cummins argues (see Figure 2 below) that learners may progress from context-embedded and cognitively undemanding material (quadrant A) to context-embedded and cognitively demanding material (quadrant B). Quadrant B represents the key area for pedagogic intervention as it makes intellectual demands in a relatively supportive environment. This staged support may enable students to handle the linguistically and cognitively demanding, context-reduced material typical of academic discourse. 
Cummins' (1996) model makes use of intersecting and interacting continua rather than stages of difficulty (as in Bloom). This model of intellectual progress suggests a far more complex understanding of the relationship between language and concept development and of factors such as interpersonal mediation and the role of identity, culture and experience in shaping the learning process.

\section{Practice outcomes and assessment: constructive alignment}

The second premise of this paper is that in order to teach higher order skills we need to align assessment practices with pedagogy and intended outcomes. University teachers have generally focused on course content and teaching and learning activities as the key determinants in shaping student learning. However, research into higher learning has shown that assessment plays a major role in shaping student learning. Ramsden (in Biggs, 1999:141) says, 'from our students' point of view, assessment always defines the actual curriculum'. Biggs refers to this phenomenon as the 'backwash effect' in which assessment determines what students learn. Traditionally, however, some teachers would see learning outcomes determining the learning and assessment 'tacked on' at the end of the teaching process. This has been termed the real 'curriculum in action' as opposed to the 'espoused curriculum' as 'for students it is their knowledge and expectations of what will be assessed that largely determines what they will learn' (Nightingale, 1996:7).

Biggs's (1999) concept of constructive alignment is useful for designing courses where the assessment performances required of students are specified in terms of learning outcomes which state the levels of understanding. All the components in an aligned system (learning outcomes, teaching and learning activities and assessment) are mutually supportive and are an integral part of the whole system. Biggs argues that when there is alignment between what we teach, how we teach it and how we assess it, teaching is likely to be much more effective than when there is not. Biggs model of instruction (1996:360) suggests that:

- 'Teachers need to be clear about what they want their students to learn, and how they would manifest that learning in terms of "performances of understanding". For example, memorizing and paraphrasing are not performances of understanding, recognizing an application in a novel context is.

- The performance objectives ... need to be arranged in a hierarchy from the most acceptable to barely satisfactory, which hierarchy becomes the grading system.

- Students need to be placed in situations that are judged likely to elicit the required learning.

- Students are then required to provide evidence, either by teacher-set or self-set tasks, as appropriate, [so] that their learning can match stated objectives'.

Although the Biggs's model of instruction may seem overly 'neat' and rather technicist, it does provide a useful guide for conceptualizing a course. This can be seen in foundation courses which have become an opportunity for course developers to deepen student learning and avoid negative backwash by providing an environment where outcomes, teaching and learning activities, and assessment practices are coherently matched. The modes of assessment have been consciously selected on the basis of the kinds of learning they are likely to elicit. 


\section{THE VALUE OF SHORT ANSWER QUESTIONS IN PROMOTING STUDENT LEARNING}

This paper focuses specifically on the 'backwash effect' of short answer questions as compared to longer essay questions. We have examined the relationship between learning outcomes, pedagogy underpinning the Foundation courses, and short answer questions as a mode of assessment.

Traditionally, assessment practices in the Humanities Faculty at Wits have relied heavily on the long essay format, both in formative assessment of term work and in summative assessment in examinations at the end of a course. One of the many alternative modes of assessment to be introduced in exams has been short answer questions. It has been a much debated issue and one which has still not been accepted by all mainstream academics.

The case studies presented explore some of the principles of constructive alignment with specific reference to short answer questions. While it has often been argued that short answer questions assess lower order skills of factual recall (Bloom's categories of 'knowledge' and 'comprehension'), we use case studies of short answer examination papers to explore the role of short answer questions in the assessment of higher order skills. Each of the case studies addresses different kinds of challenges posed by using short answer questions to promote deep learning.

\section{Visual Literacy case study}

Visual Literacy uses a question in two parts from an examination paper set at the end of the first module of the course in mid 1999 as its case study. See Figure 3.

In this instance, the short answer questions in Section 1 scaffold student responses to the increasingly complex tasks demanded in Section 2. Jones and Grant (1991) make the point that the key issue in setting questions is to be aware that different types of questions will supply different types of information about a student's abilities. The model in the Visual Literacy exam paper of the short answer prelude to the longer essay question, functions to grade the skills being assessed. In terms of Bloom's taxonomy the short answers required by Question 1, assess both the lower order skills of 'knowledge' (familiarity with examples) and 'comprehension' (understanding of key concepts), as well as the middle order skill of application (exemplification of concepts). These short answers help to scaffold the assessment of higher order skills implicit in Question 2. These higher order skills are application (application of knowledge from one context to another), analysis (comparison of the two different examples and of the relationship between history, meaning and medium), and synthesis (the ability to combine elements from different parts of the course into a cohesive discussion).

The relationship between the short answers required in Question 1 and the longer essay demanded by Question 2, also acts to scaffold the essay part of the question, by highlighting for the student those key issues about which he/she needs to demonstrate his/her understanding. In doing this, the initial short answers function de facto as an introduction to the longer essay answer in Question 2. This deliberate scaffolding of both question and answer often encourages a more discursive approach rather than a 'shopping list' of responses to the topic. The shorter question format guides students 'away from the habit of 
filling up space with information, towards a recognition that information is useful ... in proportion to the degree that it is used '(Brown \& Knight, 1994: 66). In addition therefore to the skills of knowledge, comprehension and analytical abilities, it can also be argued that short answer questions assess the ability to be concise, focused and to the point.

\section{VISUAL LITERACY FOUNDATION COURSE JUNE 1999 ANSWER BOTH QUESTIONS}

The paper is worth 100 marks

\section{QUESTION 1}

History is represented through different mediums.

What do you understand by the term representation?

(15 marks)

What do you understand by the term medium

(15 marks)

\section{USE EXAMPLES TO SHOW YOUR UNDERSTANDING}

\section{QUESTION 2}

Given your understanding of the above terms, compare different ways in which history is represented. Pay attention to the medium used. Choose ONE example from Group A and ONE from Group B

GROUP A

- Any ONE display from MuseumAfrika

- 'Soweto: A History'

- 'Kliptown Yesterday: The Story of a Living Monument'

- 'Kliptown: A Living Monument'

- 'Memorials without Facts' by Clive van den Berg

GROUP B

- Any ONE display from the Clothing and Identity exhibition

- Hector Petersen Memorial

- Memorial site of Freedom Square

- 'Off the Wall' at the Sandton Gallery

- 'Dora Nhlantswana' by Keith Deitrich

- 'Saartijie Baartman' by Penny Siopis

- 'Dora and the Other Woman' by Penny Siopis

(70 marks)

Figure 3: Visual Literacy Foundation Course Examination Questions, June 1999.

Furthermore, the short answer questions signal for students that this essay demands a focused argument in relation to specific issues. Brown and Knight (1994) draw on Hounsell's distinction between:

- essays that are arrangements of ideas

- viewpoint essays where students tend to ignore inconvenient facts and present personalized interpretations rather than present arguments

- $\quad$ argument essays 
Students' marks are influenced by their conceptions of essay writing (arrangement, viewpoint or argument) and students need to be taught what an argument essay entails. Setting short answer questions which require students to focus on issues central to an argument is a way of developing higher order thinking and argument structure.

In addition to this crucial role in both assessing and developing higher order skills, short answer questions may thus also serve a seminal and constructive role in formative assessment. The focused requirement of the short answer emphasizes very specific knowledge and comprehension and may highlight the gaps in a student's understanding often with stark clarity. Longer open-ended essays allow for students to develop areas they know and understand and allow students to present 'the bigger picture' in a more holistic sense. However, open-ended essays also allow students to sidestep those issues they are unclear about, both in terms of conceptual understanding and factual detail. In this sense, short answers may assess where students still need to develop and so may inform future teaching and learning in the course in a very direct way. This is particularly useful where two modules are linked in a year long foundation course.

It is important, however, to be alert to Cummins' (1996) notion of linguistic competency and to the way in which this may further disadvantage students who are operating in an additional language. The extended essay can provide more contextually embedded support (in Cummins' terms) while the short answer is often cognitively demanding and context-reduced. In addition, it requires students to express their ideas succinctly 'by means of language itself'.

\section{AELS case study}

Figure 4 shows a section of the AELS examination paper. In order to prepare students to handle the requirements of the assessment tasks, course materials include:

- notes explaining reasons for using evidence in academic writing

- explanations of different types of evidence

- examples of what counts as acceptable evidence

- explanations and examples of what constitutes plagiarism

- explicit examples of different methods of quotation and paraphrase

The initial intention behind this question was to test students' recall and understanding of the concepts pf plagiarism and evidence. The questions were constructed almost directly from the course materials described above. Our expectation was that the students would simply be able to reproduce the definitions required. In addition, the question aimed to test application of the academic skills of quoting and paraphrasing. Until the marking had been completed, we did not anticipate the difficulties embedded in these questions. Questions 2.1, 2.2 and 2.3 were not as straightforward as they appear to be. Plagiarism and the rules of evidence are conceptually complex and are usually new to first year students. The students need a depth of understanding and the ability to use language confidently and concisely in order to explain adequately. Plagiarism and the rules of evidence are specialist terms, taken for granted by the discourse community of academic specialists. Our new recruits to the community are not necessarily sufficiently familiar with the discourse and practices around these concepts. On reflection, these questions require higher-order, meta-awareness of what learning and understanding in the discipline demands (Perkins, 1992). 
The task words used in the above questions belie the challenges involved. The words 'give', 'quote', 'explain' could perhaps on reflection, have been worded differently to include words such as 'apply', 'relate' and 'analyse' in order to guide students to think more conceptually.

\section{QUESTION 2 EVIDENCE}

2.1 What is plagiarism and why are students and academics expected to avoid it?

2.2 Give two reasons for using evidence in academic texts.

2.3 The writer of the article (which is attached to this examination paper) uses a number of different types of evidence to support his views on the nature of teenage magazines.

Give examples of two different types of evidence in the section headed 'Pleasure: Identity and the Ideal'. (par 6-12)

In your answer:

- quote the evidence used

- explain what type of evidence it is

- say whether it comes from a primary or secondary source.

2.4 Select one short extract from the article (3 or 4 lines) which particularly interests or annoys you and explain why it does so. (This answer should be written as one paragraph).

In doing so you should both:

- quote the passage and

- paraphrase it using the appropriate referencing conventions

(20 marks)

Figure 4: Applied English Language Foundation Course Examination Questions, June 2000

The intention behind Question 2.4 was to get students to display their mastery of what was and paraphrase a short passage from an article. This article was given to students some time before the exam in order to allow for detailed and intensive reading preparation. In addition, students were given explicit models and opportunities to practise these skills in class. Despite all these preparatory strategies, the students seemed ill-equipped to deal with answering the question. In an attempt to explain some of the difficulties the following issues were identified:

- Many of the students left out this question altogether even though the question was only the second of five sections on the paper. This avoidance suggests that some aspect of the question was daunting to them. Perhaps what the examiners considered to be simply technical was in fact far more complex. 
- The question required students to skim, scan and then select from the passage something which interested and annoyed them. This requirement to make a judgement was different from the previous questions. In performing this task students had to integrate, quote, reference, paraphrase and justify their choice through the medium of a well-constructed and coherent paragraph. This meant that students needed to focus on several relevant features at once, and integrate them into a coherent whole. Students had to select an extract from the text and justify that selection. In Biggs's terms (Figure 1), unlike the first three questions in the section which simply demanded a unistructural response, the task required both multistructural and relational processing. Task words such as 'assess', 'evaluate' and 'reflect' may well have promoted better answers.

- The skills needed for Question 2.4 are those often required in longer pieces of academic writing such as long essays or dissertations. Ironically, students were required to perform these skills in a very short time and under demanding exam conditions. Once again, they needed to express their responses using concise language.

- Concise writing such as this demands a high level of linguistic competence. Many students have 'limited text processing abilities ... do not recognize author intent, ... have difficulty in differentiating main ideas from supporting ones and ... in compressing information ...' (Brinton, 1999:1). In the article given to the students before the exam, the author (Misson) discusses the influence of teenage magazines on teenagers' identities and argues that boys and girls are differently positioned by these magazines. Most students read the article as if it were simply an exposition of the nature of teenage magazines rather than as an argument expressing the intent or position of the author, They failed to differentiate between the content of teenage magazines and the author's analysis of, and position on that content.

- Using Cummins (1996) to explain the difficulties, we suggest that although class activities and exam preparation had provided support and scaffolding for tackling cognitively challenging tasks, students proved unable to meet the demands of a contextreduced situation where they were required to express complex understandings using concise language.

- A further issue of difficulty concerns the students' struggle to paraphrase. In the examination, many of the students omitted to answer the paraphrase section. Attempts to paraphrase were often completely inarticulate. They could not reframe the original text in an academic style. In Bakhtin's terms, they 'were unable to reproduce the styles and expression of the transmitted text' (Bakhtin in Starfield, 1999:92). When asked however, to select an 'extract from the article which particularly interests or annoys you', students coped well. In fact their answers displayed an enthusiasm and enjoyment suggesting a kind of liberation and engagement - an opportunity to express their own ideas in their own words. By contrast, quoting and paraphrasing were much more difficult. Starfield's explanation is illuminating. She argues that these skills of quoting and paraphrasing are 'highly contextualized social and discursive practice(s), shaped by the writer's access to textual and social power. To be a successful student one should be able to cite accurately and reference correctly but how student writers develop the linguistic and discursive authority to feel 'empowered' to engage with the more powerful words of 'authorities', is a more complex issue' (Starfield, 1999:100). 
Our students were simply not yet to engage with the 'authorities' in this way, despite all the mediation and scaffolding procedures that are built into the course. The short answer questions that we thought would be 'easy', turned out to be very demanding.

\section{Environmental Issues Case Study:}

\section{Geography Case Study:}

Figure 5 is part of an examination paper set in the Environmental Issues Foundation course. An analysis of these examination questions raises a number of issues:

\section{SECTION D: GLOBAL DYNAMICS}

\section{ANSWER ALL OF THE FOLLOWING SHORT QUESTIONS}

7. What is meant by Gross Domestic Product (GDP) and Gross National Product (GNP)? Explain why using GNP and/or GDP to measure and compare a country's status can be problematic.

8. The South African "Apartheid City" was designed around six interrelated planning criteria. Identify three of these criteria and include an example (from an urban area you are familiar with) of each in your discussion.

9. The population pyramid below shows the age-sex structure of the migrant population in the former West Germany.

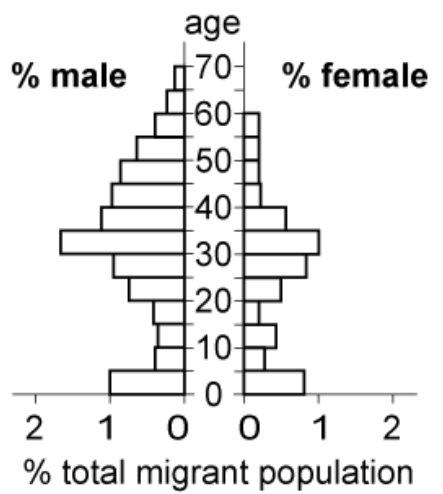

9.1 What percentage of the migrant population is aged between 20 and 45

9.2 Are there more male or female migrants? Give two reasons why this should be the case.

9.3 What would be the advantages and disadvantages for a country like West Germany receiving immigrants of the age group and sex ratios shown in the pyramid?

Figure 5: Geography Foundation Course Examination Questions, June 1999

- Short questions often require complex answers to be compressed into a few short succinct sentences 
e.g. Question 7: 'What is meant by Gross Domestic Product (GDP) and Gross National Product (GNP)? Explain why using GNP and/or GDP to measure and compare a country's economic status may be problematic'.

This question, worth only 5 marks, demands fairly sophisticated application and critique in that it requires students to define the terms, to compare and contrast the concepts, to apply them and even critique them. This question, therefore, stretches students all the way from what Biggs terms unistructural and multistructural levels to relational and metacognitive levels.

- Cummins (1996) notion of context-embedded ideas is particularly useful for second language learners who may struggle with the demands of a task such as the one above. Question 8 introduces a 'context embedded' component of learning: 'The South African "Apartheid City" was designed around six inter-related planning criteria. Identify three of these criteria and include an example (from an urban area you are familiar with) of each, in your discussion'. Despite the political changes with the first democratic elections of 1994, the effects of effects of apartheid urban planning and the built environment continue to be felt in South Africa in very real ways. Students in this course come with a lived experience of the manifestations of the 'Apartheid City'. During the course students were taken on a field trip which helped embed their lived experiences in an historical, socio-political, spatial and economic context.

- The role of language in assessment practices continues to be of critical importance. Question 8 above places high order linguistic (and cognitive) demands on the students and has important implications for speakers of English as an additional language. In this context the role of task words is crucial and cannot be over-emphasised. On reflection, the notion of a discussion appears inappropriate. To students uninitiated in the taken-forgranted rubrics of academic literacy, the discursive requirements of the word 'discuss' may not necessarily be understood and widely accessible. The latter part of the question could more appropriately be rephrased as in Figure 6: "List and describe three of these planning criteria and give an example of each criteria drawn from an urban area you are familiar with'. The task words 'list', 'describe' and 'give an example' both scaffold and make explicit, the three tasks required by this question in a more helpful way than the vague wording of 'in your discussion'. It seems apparent therefore that the gatekeeping role of language may preclude some students from meeting the demands of complex high order tasks and may be of particular significance in short answer questions.

Despite the fact that students need to be supported and scaffolded in their thinking, short questions are often not sequenced in terms of difficulty. It is strikingly evident that the original structure of the exam as in Figure 5 starts with questions requiring sophisticated critique and metacognitive thinking (Question 7) and moves to unistructural and multistructural levels, utilising skills of recall and interpretation (Question 9). On reflection, it was useful to rethink these questions in terms of sequential development and also to revisit the language and mark allocation which, given the context of this paper, has highlighted some of the issues inherent in our assessment practices. The assessment on Global Dynamics has been reworked below, (Figure 6) and bearing in mind the issues raised above, shows a more logical resequencing of these questions. 


\section{CONCLUSION}

Foundation courses have become an opportunity for course-developers to deepen student learning and avoid negative backwash by providing an environment where outcomes, teaching and learning activities and assessment practices are coherently matched. Modes of

\section{SECTION D: GLOBAL DYNAMICS}

\section{ANSWER ALL OF THE FOLLOWING SHORT QUESTIONS}

7. The population pyramid below (Figure 1) shows the age-sex structure of the migrant population in the former West Germany.

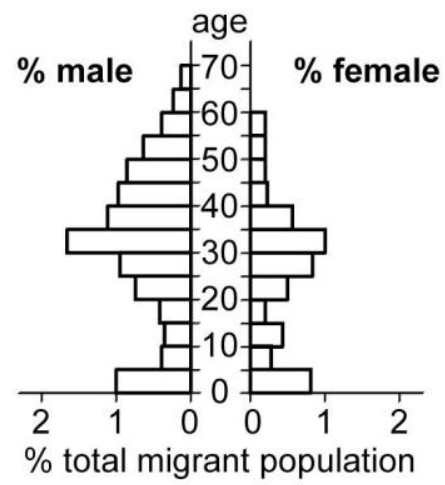

7.1 What percentage of the migrant population is aged between 20 and 45 ?

7.2 Are there more male or female migrants?

Give two reasons why this should be the case,

7.3 What would be the advantages and disadvantages for a country like West Germany receiving immigrants of the age group and sex ratios shown in the pyramid?

8. The South African "Apartheid City" was designed around six interrelated planning criteria.

List and describe three of these planning criteria and give an example of each criteria drawn from an urban area you are familiar with.

9.1 What is meant by the terms Gross Domestic Product (GDP) and Gross National Product (GNP).

9.2 Explain why using GNP and/or GSP to measure a country's economic status can be problematic.

Figure 6: Reworked Geography Foundation Course Examination Questions, June 1999

assessment need to be consciously selected on the basis of the kinds of learning that they are likely to elicit since it is hoped that, 'assessment practices play a pivotal role in helping students to move into the discourse of the subject rather than barring the way' (Dison and Rule, 1996:30). 'Good assessment now is that which closely reflects desired learning outcomes and in which the process of assessment has a directly beneficial influence on the learning process' (Boud, 1995:42). Developers of subject-based academic development programmes and disciplinary foundation courses need to be aware that assessment has 
significant implications for the way students learn and teachers teach. The influence on mainstream teaching practices of teaching and learning practices developed in foundation courses at the University of the Witwatersrand, remains the topic of another paper.

Short answer questions have traditionally been thought to elicit only lower levels of response order, as compared with essay questions, which we tend to think of as highly challenging both cognitively and linguistically. We have argued that short answer questions can be very valuably used to develop higher order thinking. In addition, we have shown how short answer questions can provide important stepping stones in guiding students into a more disciplined task-focused approach to learning. However, analysis of short answer questions from the case studies in this paper, has also demonstrated that the setting of short answer questions presents certain challenges and requires careful consideration of the role of language itself, particularly with cognitively demanding context-reduced material. The theories of Cummins, Brinton, Biggs and Bakthin have helped us realize that the learning outcomes we defined in the courses and in assessment practices, sometimes failed to take account of the difficulties experienced by students in dealing with the complex and multidimensional cognitive, linguistic and discursive challenges facing them in their endeavours to acquire academic literacy.

\section{REFERENCES}

ANDREW, D. 1998. Teaching visual literacy skills through an integrated Arts programme, Unpublished paper, University of the Witwatersrand.

ALFRED, L, M DISON \& L HAGEMEIER. 2000. Developing a sociology foundation course: an analysis of principles, methods and materials. South African Journal of Higher Education, 14(3):112-119.

BIGGS, J. 1982. Evaluating the Quality of Learning: The SOLO Taxonomy (Structure of Learning Outcome). New York: Academic Press.

BIGGS, J. 1996. Enhancing teaching through constructive alignment. Higher Education 32:118.

BIGGS, J. 1999. Teaching for Quality Learning at University. Buckingham: Society for Research into Higher Education and Open University Press.

BLOOM, B. 1956. The Taxonomy of Educational Objectives: The Classification of Education Goals. New York: D. McKay.

BRINTON, D. 1999. Academic literacy: Expectations, realities, recommendations. Unpublished USIS presentation, University of the Witwatersrand.

BROWN, S \& P KNIGHT 1994. Assessing learners in higher education. London: Kogan Page.

BOUD, D. 1995. Assessment and learning: Contradictory or complementary? In Knight, P (Ed), Assessment for Learning in Higher Education. London: Kogan. 35-48. 
CUMMINS, J. 1996. Negotiating identities: Education for empowerment in a diverse Society. Ontario C.A.: CABE.

DISON, L \& P RULE. 1996. Bridging the subject-student divide: An integrated approach to developing foundational curricula. Academic Development, 2 (2): 83-97.

FOUNDATION IN ENVIRONMENTAL ISSUES FLIER. 2005. School of Geography, Archaeology and Environmental Studies, Faculty of Humanities, University of the Witwatersrand.

JONES, J \& B GRANT. 1991. Writing, Setting and Marking Essays. Auckland: Higher Education Research Office, University of Auckland.

LAURILLARD, D. 1993. Rethinking university teaching: A framework for effective use of educational technology. London: Routledge.

LUCKETT, K (Ed.). 1996. Curriculum development: Reflecting on our practice. South African Association for Academic Development, Curriculum Development Workshop.

NIGHTINGALE, P. 1996. Assessing learning in universities. Sydney: University of New South Wales Press.

PERKINS, D. 1992. Smart schools: From training memories to educating minds. New York: New York Press.

RAMSDEN, P. 1992. Learning to teach in higher education. London: Routledge.

RESNICK, L. 1987. Education and learning to think. Washington D.C.: National Academy Press.

ROWNTREE, D. 1987. Assessing students: how shall we know them? London: Kogan Page.

STARFIELD, S. 1999. Making and sharing meaning: the academic writing of first year students in the Department of Sociology who speak English as an additional language. Unpublished PhD thesis, University of the Witwatersrand.

TOOHEY, S. 1999. Designing courses for higher education. Buckingham: Society for Research into Higher Education and Open University Press.

\section{Bibliographical Note}

All of the authors are currently at the University of the Witwatersrand. Cheryl Chamberlain is at Geography, Archaeology and Environmental Studies; Alison Button and Laura Dison are teaching and learning advisors in the Humanities Faculty; Stella Grenville is at the School of Literature and Language Studies; and Elizabeth Delmont is at the Wits School of Arts.

*Corresponding author is Cheryl Chamberlain: email: Chamberlainc@geoarc.wits.ac.za 